\title{
Direct Torque Control of Saturated Doubly-Fed Induction Generator using High Order Sliding Mode Controllers
}

\author{
Elhadj BOUNADJA \\ Department of Automatic \\ Ecole Nationale Polytechnique \\ Elharrach, Algiers, Algeria \\ Mohand Oulhadj MAHMOUDI \\ Department of Automatic \\ Ecole Nationale Polytechnique \\ Elharrach, Algiers, Algeria
}

\author{
Abdelkader DJAHBAR \\ Department of Electrical Engineering \\ University HASSIBABENBOUALI \\ Chlef, Algeria
}

\author{
Mohamed MATALLAH \\ Department of Technology \\ University DJILALI BOUNAAMA \\ Khemis Meliana, Ain defla, Algeria
}

\begin{abstract}
The present work examines a direct torque control strategy using a high order sliding mode controllers of a doublyfed induction generator (DFIG) incorporated in a wind energy conversion system and working in saturated state. This research is carried out to reach two main objectives. Firstly, in order to introduce some accuracy for the calculation of DFIG performances, an accurate model considering magnetic saturation effect is developed. The second objective is to achieve a robust control of DFIG based wind turbine. For this purpose, a Direct Torque Control (DTC) combined with a High Order Sliding Mode Control (HOSMC) is applied to the DFIG rotor side converter. Conventionally, the direct torque control having hysteresis comparators possesses major flux and torque ripples at steady-state and moreover the switching frequency varies on a large range. The new DTC method gives a perfect decoupling between the flux and the torque. It also reduces ripples in these grandeurs. Finally, simulated results show, accurate dynamic performances, faster transient responses and more robust control are achieved.
\end{abstract}

Keywords-Doubly Fed Induction Generator (DFIG); Magnetic saturation; Direct Torque Control (DTC); High Order Sliding Mode Controller (HOSMC)

\section{INTRODUCTION}

Recently, worldwide awareness for renewable energy resources has been increasing. In particular, wind energy has been largely considered because of its economy and reliability. Wind turbines contribute a certain amount of the word electricity consumption [1]. They usually use a Doubly-Fed Induction Generator (DFIG) for the electrical energy conversion process. As deduced from literature, many workers investigate the DFIG from diverse aspects. However, in these works, many simplifying hypotheses are considered in the modelling of the DFIG, with the neglect of magnetic saturation being the most important as in [1-10]. However, the phenomenon of saturation is present in all electrical machines. In addition, the exact calculation of the machine dynamic performances depends considerably on the saturation of the mutual and leakage fluxes [11-17]. Because of this reason and in order to realize an accurate representation of the DFIG, saturation must be taken into account in their mathematic modelling. Consequently, an accurate DFIG model taking into account the saturation effect both in mutual flux and in leakage fluxes is used in this paper.

After major advances in power electronics and material technologies, many works have presented the DFIG with different control algorithms. One of the conventional control schemes used actually for the DFIG-based wind turbine is the Direct Torque Control based on switching table and hysteresis comparators [18]. This strategy, however, has a few disadvantages which limit its use, such as variable switching frequency and torque ripple $[19,20]$. In many research works on DTC, these disadvantages are reduced by using SVM scheme, but with the price of scarifying the robustness of the control [21].

To incorporate a robust DTC without torque and flux ripples, we propose, in the present work, a direct torque control based on high order sliding mode controllers (DTC-HOSMC) for a DFIG in saturated state. Proposed by Levant in [22] the HOSMC strategy has many attractive features such as its robustness towards parametric uncertainties of the DFIG, and moreover, it reduces the chattering effect.

The present work provides the important features of the DTC-HOSMC and presents simulation results for a DFIG system. We compare the proposed strategy with a conventional DTC. The present paper is organized as follows: we present the modelling of the wind turbine and the DFIG using the saturated model in section II. In section III, the proposed DTC-HOSMC, is applied to control the saturated DFIG. The implementation and the results obtained from the proposed controller are shown in section IV. Finlay, it will be shown that using the developed DFIG model and the proposed controller, the dynamic responses of the system can be determined accurately and more precise robust control is achieved. 


\section{MODELING OF WIND ENERGY CONVERSION SYSTEM}

The wind energy conversion system adopted in this work is based on wind turbine driven a DFIG. In such configuration, the stator is directly connected to the network, whereas, the rotor is fed by the grid via two converters (AC/DC) and (DC/AC). In addition, the rotor side converter (DC/AC) is used to control independently the DFIG active and reactive powers.

\section{A. Modeling of the wind turbine}

The mechanical power captured from the wind turbine, used in this investigation, is expressed as below:

$$
P_{t}=0.5 C_{P}(\lambda, \beta) R^{2} \rho v^{3}
$$

With:

$R$ : radius of turbine $(\mathrm{m}), \rho$ : density of air $(\mathrm{kg} / \mathrm{m} 3), v$ : speed of wind $(\mathrm{m} / \mathrm{s})$ and $C_{P}$ : the power coefficient.

According to [3], the power coefficient $C_{p}$ is function of the tip speed ratio $\lambda$ and the blade pitch angle $\beta$ (deg), as follows:

$$
C_{p}=0.5109\left(\frac{116}{\lambda_{i}}-0.4 \beta-5\right) \exp \left(-\frac{21}{\lambda_{i}}\right)+0.0068 \lambda
$$

With:

$$
\frac{1}{\lambda_{i}}=\frac{1}{\lambda+0.08 \beta}-\frac{0.035}{\beta^{3}+1}
$$

The tip speed ratio $\lambda$ is given by:

$$
\lambda=\frac{\Omega_{\mathrm{t}} \mathrm{R}}{\mathrm{V}}
$$

In (4) $\Omega_{t}$ represent the rotational speed of the wind turbine.

\section{B. Modeling of the DFIG}

Below, we develop the conventional model of the DFIG without saturation. According to this model, both mutual flux and leakage fluxes saturation are considered. In these models, the DFIG is considered as a generalized wound rotor induction machine taking the stator resistance into consideration. The latter is neglected in many works e.g. in [1-19].

\section{1) Linear DFIG model}

The $d$ and $q$ equivalents circuits for the DFIG are shown in Fig. 1 [15]. Based in these schemas, the voltages equations of the DFIG in the $d-q$ synchronous referential are given by:

$$
\left\{\begin{array}{l}
v_{s d}=R_{s} i_{s d}+\frac{d}{d t} \psi_{s d}-\omega_{s} \psi_{s q} \\
v_{s q}=R_{s} i_{s q}+\frac{d}{d t} \psi_{s q}+\omega_{s} \psi_{s d} \\
v_{r d}=R_{r} i_{r d}+\frac{d}{d t} \psi_{r q}-\omega_{r} \psi_{r q} \\
v_{r q}=R_{r} i_{r q}+\frac{d}{d t} \psi_{r q}+\omega_{r} \psi_{r d}
\end{array}\right.
$$

Where the rotor frequency $\omega_{r}$ is given by:

$$
\omega_{r}=\omega_{s}-\omega_{m}
$$

The flux linkages in (5) are obtained from the following equation system:

$$
\left\{\begin{array}{l}
\psi_{s d}=L_{s} i_{s d}+L_{m} i_{r d} \\
\psi_{s q}=L_{s} i_{s q}+L_{m} i_{r q} \\
\psi_{r d}=L_{r} i_{r d}+L_{m} i_{s d} \\
\psi_{q r}=L_{r} i_{q r}+L_{m} i_{q s}
\end{array}\right.
$$

The equation system in (7) is used to calculate the $d$ and $q$ components of stator and rotor currents:

$$
\left\{\begin{array}{l}
i_{s d}=\frac{1}{\sigma L_{s} L_{r}}\left(L_{r} \psi_{s d}-L_{m} \psi_{r d}\right) \\
i_{s q}=\frac{1}{\sigma L_{s} L_{r}}\left(L_{r} \psi_{s q}-L_{m} \psi_{r q}\right) \\
i_{r d}=\frac{1}{\sigma L_{s} L_{r}}\left(L_{s} \psi_{r d}-L_{m} \psi_{s d}\right) \\
i_{r q}=\frac{1}{\sigma L_{s} L_{r}}\left(L_{s} \psi_{r q}-L_{m} \psi_{s q}\right)
\end{array}\right.
$$

With:

$$
\sigma=1-\frac{L_{m}^{2}}{L_{s} L_{r}}, L_{s}=L_{s \sigma}+L_{m}, L_{r}=L_{r \sigma}+L_{m}
$$

The magnetizing current $i_{m}$ is given as follows $[14,15]$ :

$$
i_{m}=\sqrt{i_{m d}^{2}+i_{m q}^{2}}
$$

Where:

$$
i_{m d}=i_{s d}+i_{r d}, i_{m q}=i_{s q}+i_{r q}
$$

In steady state and by aligning the q-axis of synchronous rotating reference frame on stator flux vector, the following equations can be written $[2,8]$ :

$$
\begin{gathered}
\psi_{d s}=\psi_{s}=\frac{V_{s}}{\omega_{s}}, \quad \psi_{q s}=0 \\
\psi_{r}=\sigma L_{r} i_{r d}+\frac{L_{m} V_{s}}{L_{s} \omega_{s}} \\
\left\{\begin{array}{l}
v_{r d}=R_{r} i_{r d}+L_{r} \sigma \frac{d i_{r d}}{d t}-g \omega_{s} L_{r} \sigma i_{r q} \\
v_{r q}=R_{r} i_{r q}+L_{r} \sigma \frac{d i_{r q}}{d t}+g \omega_{s} L_{r} \sigma i_{r d}+g \omega_{s} \frac{L_{m} V_{s}}{L_{s} \omega_{s}} \\
T_{e m}=-p \frac{L_{m} V_{s}}{L_{s} \omega_{s}} i_{q r}
\end{array}\right.
\end{gathered}
$$




\section{2) DFIG model with saturation}

Using the linear model explained in the previous section, we develop a DFIG model taking the mutual flux saturation into consideration. The corresponding saturated value $L_{m s}$ replaces the unsaturated mutual inductance $L_{m}$ in this approach, (7)-(9). This saturated mutual inductance is calculated by multiplying the corresponding unsaturated value, $L_{m}$, with a saturation coefficient $K_{s m}$, corresponding to the saturation state.

The saturated mutual inductance $L_{m s}$, which is a function of the magnetizing current $i_{m}$, can be written as follows:

$$
L_{m s}=\left\{\begin{array}{lc}
L_{m} & i_{m}<I_{m s a t} \\
K_{s m}\left(i_{m}\right) \cdot L_{m} & i_{m} \geq I_{m s a t}
\end{array}\right.
$$

The saturation coefficient $K_{s m}$ can be represented by the function [11]:

$$
K_{s m}\left(i_{m}\right)=\left\{\begin{array}{lr}
1 & i_{m}<I_{m s a t} \\
\frac{2}{\pi}\left[\arcsin \left(\frac{I_{m s a t}}{i_{m}}\right)+0,5 \sin \left(2 \arcsin \left(\frac{I_{m s a t}}{i_{m}}\right)\right]\right. & i_{m} \geq I_{m s a t}
\end{array}\right.
$$

Here $I_{m s a t}$ represents the magnetizing current at which the saturation starts. It is around $0.5 p u$, i.e $0.7 \times I_{n}[14,25]$.

In addition, in the modelling of DFIG, the representation of saturation includes the variation in the stator and rotor leakage inductances caused by the saturation in the leakage flux paths. The saturation in the leakage flux paths is taken into account in the model developed in previous section by replacing the unsaturated stator and rotor leakage inductances $\left(L_{s \sigma}, L_{r \sigma}\right)$ in (9) by their corresponding saturated values $\left(L_{s \sigma s}, L_{r G s}\right)$. The latter inductances are obtained by multiplying their respective unsaturated values by a saturation coefficient $K_{s \sigma}$. This coefficient depends to the stator current or the rotor current.

The stator and rotor leakage inductances are given as function of their corresponding currents as follows:

$$
\begin{aligned}
& L_{s \sigma \sigma}\left(i_{s}\right)= \begin{cases}L_{s \sigma} & i_{s}<I_{\text {sat }} \\
K_{s \sigma}\left(i_{s}\right) \cdot L_{s \sigma} & i_{s} \geq I_{s a t}\end{cases} \\
& L_{r \sigma \sigma}\left(i_{r}\right)= \begin{cases}L_{r \sigma} & i_{r}<I_{\text {sat }} \\
K_{s \sigma}\left(i_{r}\right) \cdot L_{r \sigma} & i_{r} \geq I_{\text {sat }}\end{cases}
\end{aligned}
$$

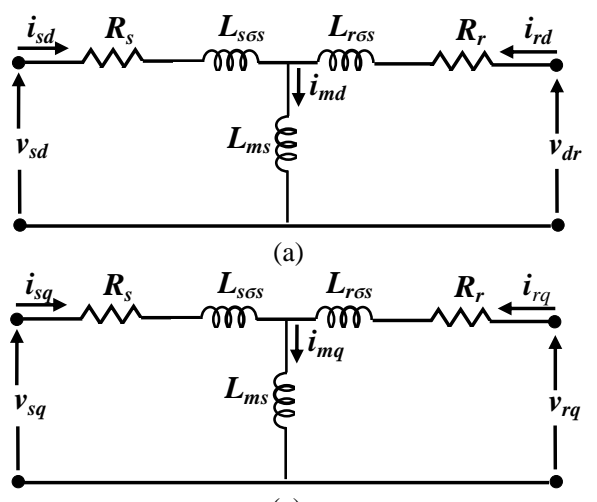

(a)

Fig. 1. Equivalent circuits of a DFIG: (a) on d-axis, (b) on q-axis
The saturation coefficient $K_{s \sigma}$ can be represented by the function [11]:

$$
K_{s \sigma}(i)= \begin{cases}1 & i<I_{\text {sat }} \\ \frac{2}{\pi}\left[\arcsin \left(\frac{I_{\text {sat }}}{i}\right)+0,5 \sin \left(2 \arcsin \left(\frac{I_{\text {sat }}}{i}\right)\right]\right. & i \geq I_{\text {sat }}\end{cases}
$$

Saturation is taken into account at values of the current $I_{\text {sat }}$ in the range $1,3-3 p u$, that is $1,8 \times I_{n}-4,2 \times I_{n}[14,26,27]$.

\section{DiReCt TORQue CONTROL USING High ORDER SLIDING MODE CONTROLLERS OF DFIG}

The goal of DTC-HOSMC is to regulate both the torque and the rotor flux magnitude of the DFIG. The flux is regulated using the direct axis voltage $V_{d r}$, while the torque is controlled using the quadrature axis voltage $V_{q r}$. The phenomenon of chattering that represents the important problem of the conventional sliding mode control can be very harmful for the DFIG due the fact that the discontinuous control can cause overheating of the coils and the excitation of unmodelled high frequency dynamics. In [28] some solutions were proposed in order to avoid this disadvantage. The main idea was to adjust the dynamics in a small region of the discontinuity surface so to escape the real discontinuity meanwhile conserving the major characteristics of the entire system. The lately proposed HOSMC generalizes the main sliding mode idea which acts on the high order time derivatives of the system deviation from the constraint in place of influencing the first deviation derivative as in standard sliding modes [6]. In addition to keeping the major advantages of the original technique, they discuss the chattering effect and even represent higher accuracy in a real implementation. In HOSMC algorithm implementations, the main difficulty consists of the increase in the needed information. In fact, the knowledge of $\dot{S}, \ddot{S}, \ldots, S^{(n-1)}$ is required to achieve an $n^{\text {th }}$ order controller. As an exception to all the algorithms proposed for the HOSMC, the super-twisting algorithm needs only the information on the sliding surface [6]. As a consequence, this algorithm has been utilized for the proposed control method. As mentioned in [28], the stability can be obtained for all high order sliding mode controllers with this algorithm. Figure 2 shows the proposed DTC-HOSMC, which is used to control both the rotor flux and the electromagnetic torque of the DFIG.

In this study, the errors between reference and measured of the electromagnetic torque and the rotor flux have been chosen as sliding mode surfaces, so the following expression can be written:

$$
\left\{\begin{array}{l}
S_{\psi_{r}}=\psi_{r_{-} r e f}-\psi_{r} \\
S_{T_{e m}}=T_{e m_{-} r e f}-T_{e m}
\end{array}\right.
$$

By substituting the rotor flux and the electromagnetic torque in (21) by their expressions given, respectively, by (13) and (15), one obtains:

$$
\left\{\begin{array}{l}
S_{\psi_{r}}=\psi_{r-r e ́ f}-\sigma L_{r} i_{r d}-\frac{L_{m}}{L_{s}} \Psi_{s} \\
S_{T_{e m}}=T_{e m-r e ́ f}+p \frac{L_{m} V_{s}}{L_{s} \omega_{s}} i_{q r}
\end{array}\right.
$$


The first derivative of (22), gives:

$$
\left\{\begin{array}{l}
\dot{S}_{\psi_{r}}=\dot{\psi}_{r-r e ́ f}-\sigma L_{r} \dot{i}_{r d} \\
\dot{S}_{T_{e m}}=\dot{T}_{e m-r e ́ f}+p \frac{L_{m} V_{s}}{L_{s} \omega_{s}} \dot{i}_{r q}
\end{array}\right.
$$

If we replace the $d$ and $q$ rotor currents derivatives in (23) by their expressions given from (14), one obtains:

$$
\left\{\begin{array}{l}
\dot{S}_{\psi_{r}}=\dot{\psi}_{r-r e ́ f}-\left[v_{r d}-R_{r} i_{r d}+g \omega_{s} \sigma L_{r} i_{r q}\right] \\
\dot{S}_{T_{e m}}=\dot{T}_{e m-r e ́ f ~}+p \frac{V_{s} L_{m}}{\sigma L_{s} L_{r}}\left[v_{r q}-R_{r} i_{r q}-g \omega_{s} \sigma L_{r} i_{r d}-g V_{s} \frac{L_{m}}{L_{s}}\right]
\end{array}\right.
$$

We define the functions $G_{l}$ and $G_{2}$ as follows:

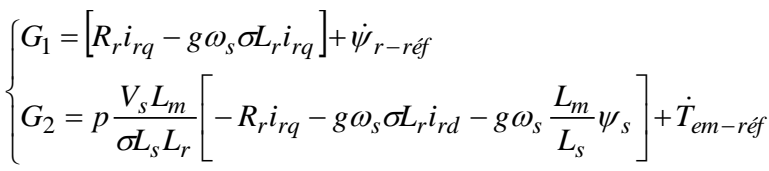

After substituting (25) in (24), the derivative of (24) gives:

$$
\left\{\begin{array}{l}
\ddot{S}_{\psi_{r}}=\dot{v}_{r d}+\dot{G}_{1} \\
\ddot{S}_{T_{e m}}=p \frac{V_{s} L_{m}}{\sigma L_{s} L_{r}} \dot{v}_{r q}+\dot{G}_{2}
\end{array}\right.
$$

Basing on the super-twisting algorithm established by Levant in $[22,23]$, the high order sliding mode controller contains two parts:

$$
\left\{\begin{array}{l}
v_{r d}=-\alpha_{1} \int \operatorname{sign}\left(S_{\psi_{r}}\right) d t-\beta_{1}\left|S_{\psi_{r}}\right|^{0.5} \operatorname{sign}\left(S_{\psi_{r}}\right) \\
V_{r q}=-\alpha_{2} \int \operatorname{sign}\left(S_{T_{e m}}\right) d t-\beta_{2}\left|S_{T_{e m}}\right|^{0.5} \operatorname{sign}\left(S_{T_{e m}}\right)
\end{array}\right.
$$

In order to guarantee the convergence of the sliding manifolds to zero in set time, the constants $\alpha_{1}, \beta_{1}, \alpha_{2}$ and $\beta_{2}$ can be chosen as follows $[2,6,28]$ :

$$
\begin{aligned}
& \left\{\begin{array}{l}
\alpha_{1}>\mu_{1} \\
\beta_{1}^{2} \geq 4 \mu_{\mathrm{i}} \frac{\left(\alpha_{1}+\mu_{1}\right)}{\left(\alpha_{1}-\mu_{1}\right)} \\
\mu_{1}>\left|G_{2}\right|
\end{array}\right. \\
& \left\{\begin{array}{l}
\alpha_{2}>\mu_{2} \frac{p V_{s} L_{m}}{\sigma L_{s} L_{r}} \\
\beta_{2}^{2} \geq 4 \mu_{2}\left(\frac{p V_{s} L_{m}}{\sigma L_{s} L_{r}}\right)^{2} \frac{\left(\alpha_{2}+\mu_{2}\right)}{\left(\alpha_{2}-\mu_{2}\right)} \\
\mu_{2}>\left|G_{2}\right|
\end{array}\right.
\end{aligned}
$$

\section{Simulation RESUlts}

In this section, simulations are realized with a $7.5 \mathrm{KW}$ DFIG coupled to a $(311 \mathrm{~V}, 50 \mathrm{~Hz})$ network, utilizing the Matlab/Simulink environment. The parameters of the machine are shown in Table 2.

The consideration of saturation into account for the mutual flux of the investigated DFIG is realized by taking $I_{m s a t}$ in (16)(17) to be equal to $0.7 \times I_{n}=6 \mathrm{~A}$. In this equality, $I_{n}$ is the rated current given in Table 2 . The mutual flux saturation coefficient
$K_{s m}$ used in the determination of the saturated value of the mutual inductance $L_{m s}$ is sketched in figure 3. Likewise, the consideration of the leakage flux saturation, $I_{\text {sat }}$ in (18)-(20) was assumed to be equal to $1.8 \times I_{n}=15.8 \mathrm{~A}$, where the leakage flux saturation coefficient $K_{s \sigma}$ is shown in figure 4.

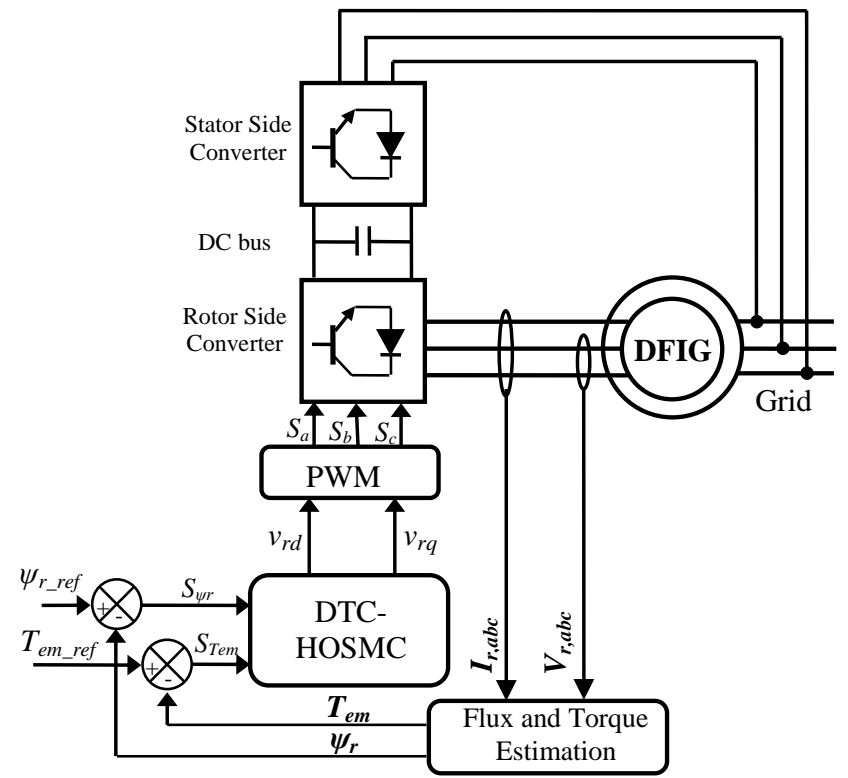

Fig. 2. Bloc diagram of HOSMC-DTC applied to the DFIG

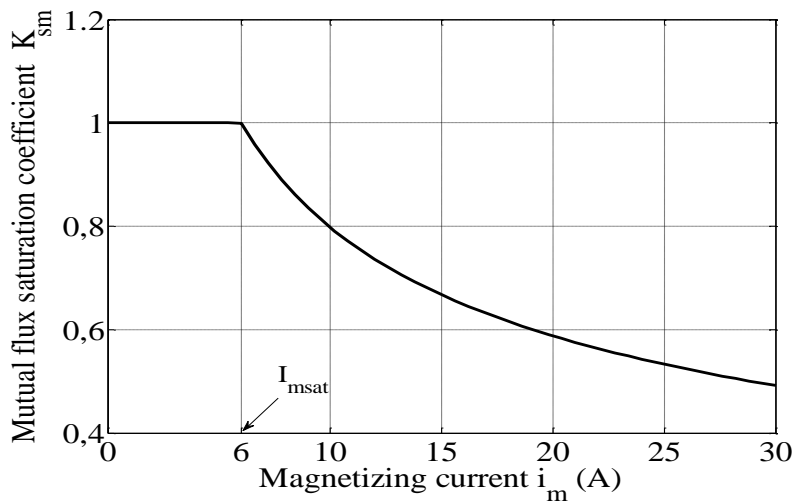

Fig. 3. Mutual flux saturation coefficient $K_{s m}$

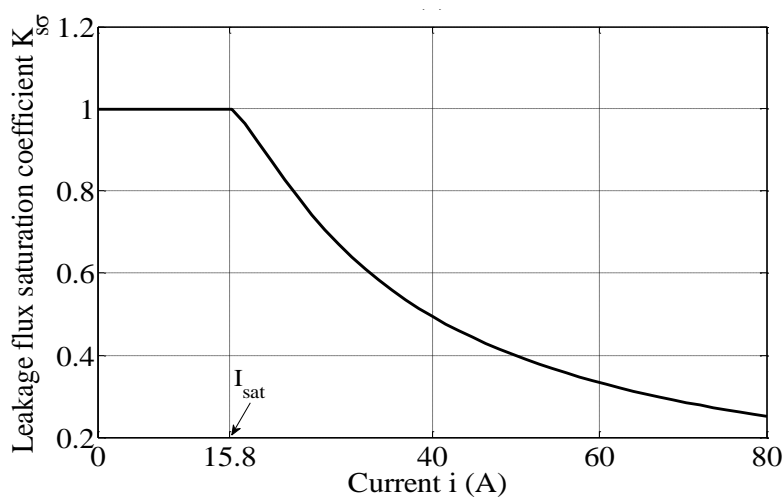

Fig. 4. Leakage flux saturation Coefficient $K_{s \sigma}$ 
The two DTC control strategies; classical DTC and DTCHOSMC are simulated and compared in terms of reference tracking and robustness against machine parameter variations.

\section{A. Test of reference tracking}

The goal of this test is to explore the behaviour of the two DTC control strategies while maintaining the DFIG's speed at its nominal value. The simulation results are shown in figures 5 and 6. From these figures we can see that for the DTCHOSMC control method, the torque and rotor flux track almost perfectly their references values. In addition, and contrary to the classical DTC strategy in which the coupling effect between the two axes is quite apparent, we remark that, in the present DTC-HOSMC strategy, the decoupling between the axes is guaranteed.

\section{B. Test of robustness}

In order to check the robustness of the used DTC control strategies, the machine parameters namely the stator and the rotor resistances $R_{s}$ and $R_{r}$ have been intentionally doubled. The DFIG is working at its nominal speed and is in state of saturation. Figures 6 and 7 show the simulation results. From these Figures, we see that the parameters variation of the machine increase the time-response of the classical DTC strategy slightly. However the results show that these variations cause a marked effect on the torque and flux variations and this effect is more marked for the classical DTC strategy than that with DTC-HOSMC.
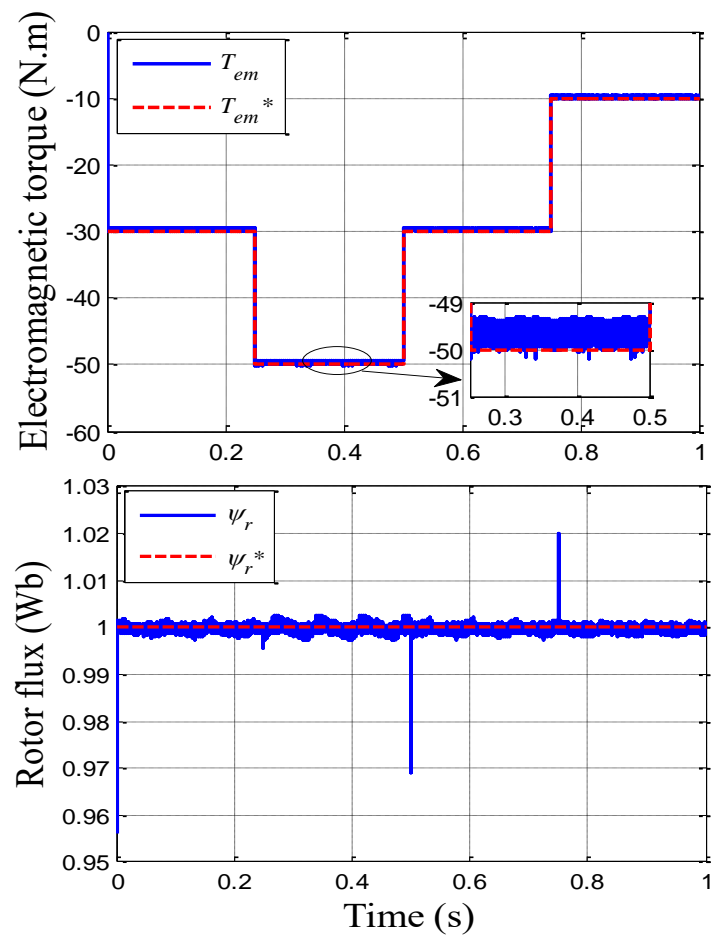

Fig. 5. Classical DTC strategy responses (reference tracking test)
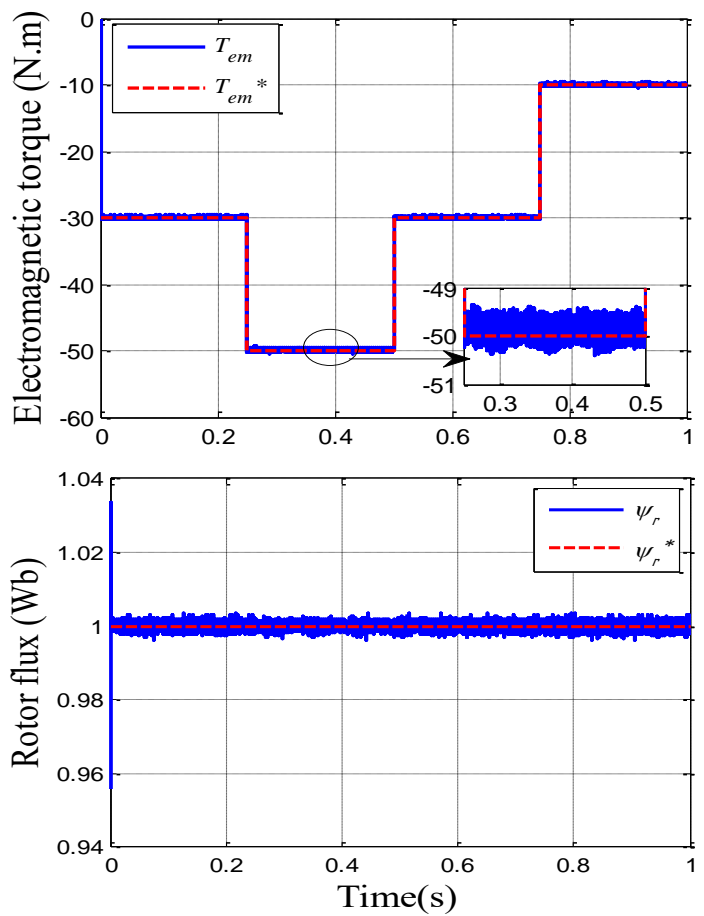

Fig. 6. DTC-HOSMC strategy responses (test of reference tracking)
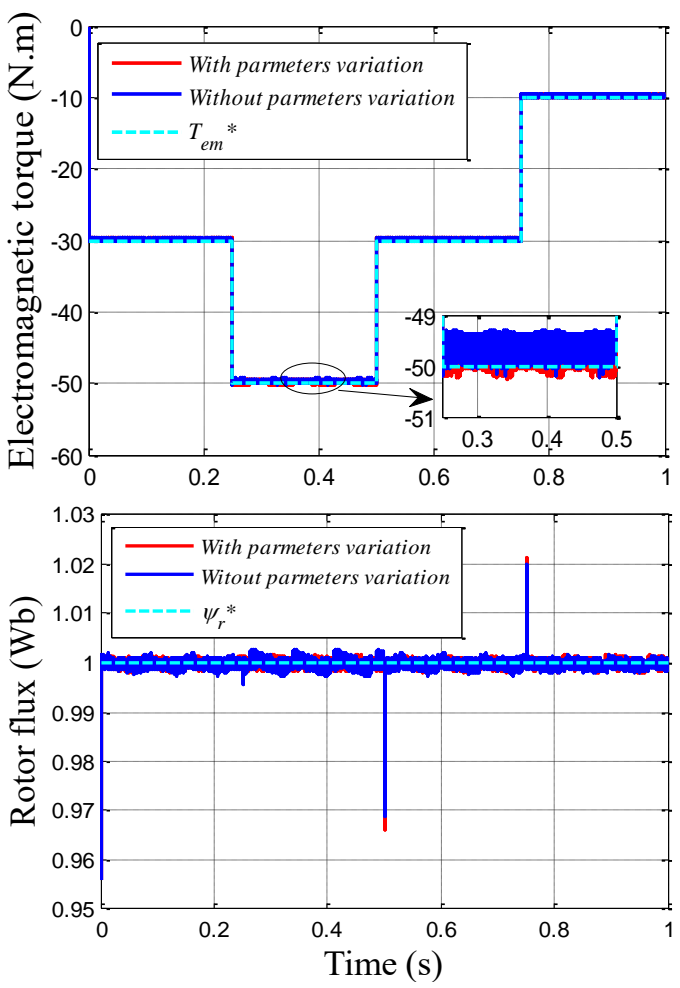

Fig. 7. Classical DTC strategy responses (test of robustness) 

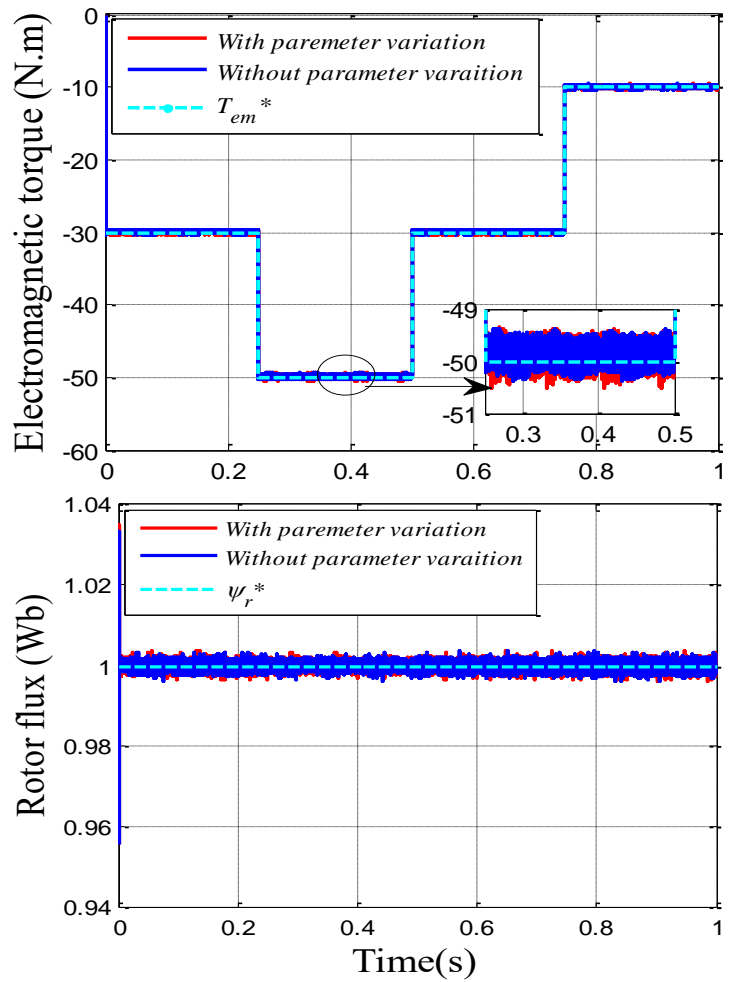

Fig. 8. DTC-SOSMC strategy responses (robustness test)
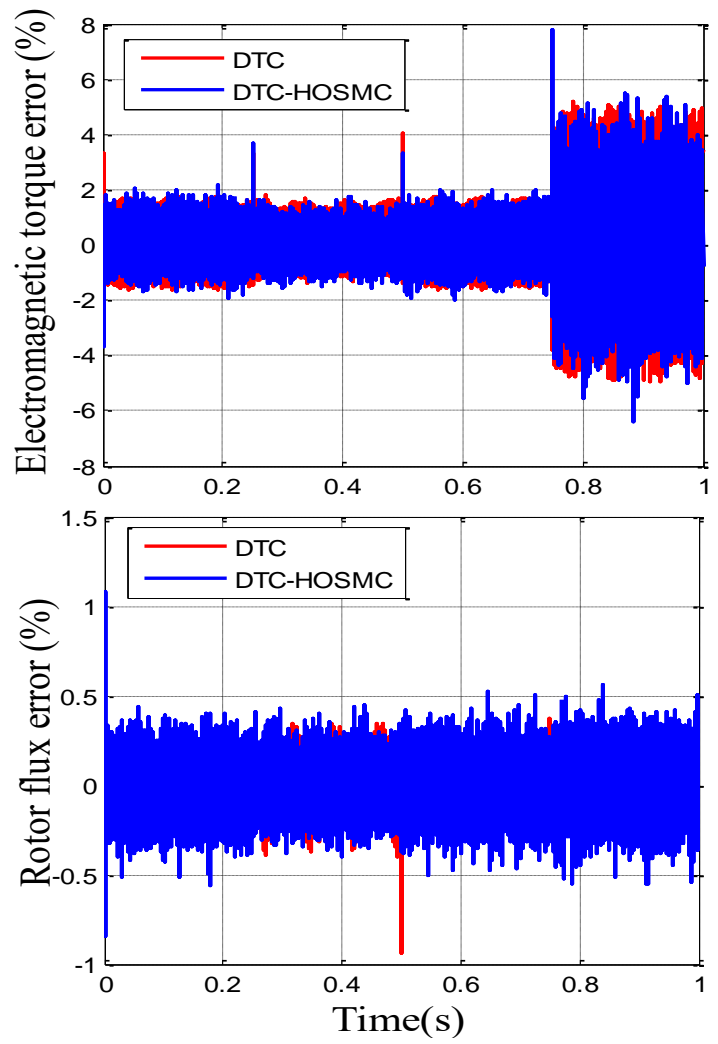

Fig. 9. Error curves (robustness test)

\section{CONCLUSION}

In this paper, we have investigated a Direct Torque Control using a high order sliding mode controllers. The goal of this control strategy has been to improve the calculation of the dynamic performances of saturated DFIG driven by a wind turbine driven. In the first place, the modelling of the saturated DFIG-based wind turbine has been carried out. The saturation of both the magnetizing flux and of the leakage fluxes have been taken into account in the proposed DFIG model. Then, the synthesis of a new DTC combined with HOSMC has been performed and this DTC-HOSMC has been compared with the conventional DTC in term of reference tracking. The tacking of their references was achieved almost perfectly by the two DTC strategies, however there appeared a coupling effect in the conventional DTC responses, whereas this coupling was eliminated in the DTC-HOSMC. An investigation of robustness test has also been realized in which the parameters of the DFIG have been intentionally modified. Some disturbances on the torque and flux responses have been induced by these changes but with a major effect with the conventional DTC strategy than with the proposed DTCHOSMC. On the light of these results, we conclude that the robust DTC-HOSMC control method is a very attractive solution for those devices that use the saturated DFIG as happens in wind energy conversion systems.

\section{APPENDIX}

\section{TABLE I. LIST OF SYMBOLS}

\begin{tabular}{|l|l|}
\hline Symbol & Significance \\
\hline DFIG & Doubly-fed induction generator \\
\hline DTC & Direct Torque Control \\
\hline HOSMC & High Order Sliding Mode Control \\
\hline$v_{d s}, v_{q s}, v_{d r}, v_{q r}$ & $d$ and $q$ axis stator and rotor voltages, \\
\hline$\psi_{d s}, \psi_{q s}, \psi_{d r}, \psi_{q r}$ & $d$ and $q$ axis stator and rotor fluxes, \\
\hline$\psi_{r_{r} r e f}$ & Reference rotor flux \\
\hline$i_{d s}, i_{q s}, i_{d r}, i_{q r}$ & $d$ and $q$ axis stator and rotor currents, \\
\hline$R_{s}, R_{r}$ & Stator and rotor resistances, \\
\hline$L_{s}, L_{r}$ & Stator and rotor inductances, \\
\hline$L_{s \sigma}, L_{r \sigma}$ & Stator and rotor leakage inductances, \\
\hline$L_{s \sigma s}, L_{r \sigma s}$ & Stator and rotor saturated leakage inductances, \\
\hline$\sigma$ & Leakage coefficient \\
\hline$I_{n}$ & Rated current, \\
\hline$L_{m}$ & Mutual inductance, \\
\hline$L_{m s}$ & Saturated mutual inductance, \\
\hline$p$ & Number of pole pairs, \\
\hline$s$ & Generator slip, \\
\hline$\omega_{s,} \omega_{r}$ & Stator and rotor current frequencies (rd/s), \\
\hline$\omega_{m}$ & Mechanical rotor frequency (rd/s), \\
\hline$T_{e m}, T_{e m} r e f$ & Electromagnetic, Reference electromagnetic torque. \\
\hline & \\
\hline
\end{tabular}

\section{TABLE II. MACHINE PARAMETERS}

\begin{tabular}{|l|l|l|}
\hline Parameters & Rated Value & Unit \\
\hline Nominal power $P_{n}$ & 7.5 & $\mathrm{KW}$ \\
\hline Stator voltage $V_{n}$ & 220 & $\mathrm{~V}$ \\
\hline Stator voltage amplitude $V_{s}$ & 311 & $\mathrm{~V}$ \\
\hline Stator current $I_{n}$ & 8,6 & $\mathrm{~A}$ \\
\hline Stator frequency $f$ & 50 & $\mathrm{~Hz}$ \\
\hline Number of pairs poles $p$ & 2 & \\
\hline Nominal speed $\boldsymbol{\omega}_{m}$ & 144 & $\mathrm{rad} / \mathrm{s}$ \\
\hline Stator resistance $R_{s}$ & 1.2 & $\Omega$ \\
\hline Rotor resistance $R_{r}$ & 1.8 & $\Omega$ \\
\hline Mutual inductance $L_{m}$ & 0.15 & $\mathrm{H}$ \\
\hline Leakage stator inductance $L_{\sigma s}$ & 0.0054 & $\mathrm{H}$ \\
\hline Leakage rotor inductance $L_{\sigma r}$ & 0.0068 & $\mathrm{H}$ \\
\hline
\end{tabular}




\section{REFERENCES}

[1] D. Kairous and B. Belmadani, "Robust Fuzzy-Second Order Sliding Mode based Direct Power Control for Voltage Source Converter", International Journal of Advanced Computer Science and Applications (IJACSA), vol. 6, no. 8, 2015, pp. 167-175.

[2] S. Abddaim, A. Betka, "Optimal tracking and robust power control of the DFIG wind turbine", Electrical Power and Energy Systems, vol. 49, 2013, pp. 234-242.

[3] A. Davigny, " Participation in the system services of wind farms variable speed integrated storage inertial energy"; $\mathrm{PhD}$ thesis, University of Lille, France, 2007.

[4] M. Edrah, K. L. Lo, O. Anaya-Lara, "Impacts of high penetration of DFIG wind turbines on rotor angle stability of power systems", IEEE Trans. Sustain Energ, vol. 6, 2015, pp. 759-766.

[5] N. Bounar, A. Boulkroune, F. Boudjema, M. M'Saad, M. Farza, "Adaptive fuzzy vector control for a doubly-fed induction motor", In: Neurocomputing, vol. 151, no. 2, 2015, pp. 756-769.

[6] B. Beltran, M.E.H. Benbouzid, T. Ahmed-Ali, "Second order sliding mode control of a doubly fed induction generator driven wind turbine, IEEE Trans., Energy Convers., Vol. 27, No 2, 2012, pp. 261-269.

[7] M. Benkahla, R. Taleb and Z. Boudjema, "Comparative Study of Robust Control Strategies for a DFIG-Based Wind Turbine”, International Journal of Advanced Computer Science and Applications (IJACSA), vol. 7, no. 2, 2016, pp. 455-462.

[8] F. Poitiers, T. Bouaouiche, M. Machmoum, "Advanced Control of a Doubly-Fed Induction Generator for Wind Energy Conversion", Electric Power Systems Research, vol. 79, no 7, 2009, pp.1085-1096.

[9] X. Zhu, S. Liu, Y. Wang, "Second-order sliding-mode control of DFIGbased wind turbines", In: IEEE $3^{\text {rd }}$ Renewable Power Generation Conference, 24-25 September 2014; Naples, Italy, pp. 1-6.

[10] S. Z. Chen, N. C. Cheung, K. C. Wong, J. Wu, "Integral sliding-mode direct torque control of doubly-fed induction generators under unbalanced grid voltage", IEEE T Energy Conver, vol. 25, 2010, pp. 356-368.

[11] L. Monjo, F. C'orcoles, J. Pedra, "Saturation Effects on Torque and Current Slip Curves of Squirrel Cage Induction Motors", IEEE transactions on energy conversion, vol.28, No1, 2013, pp. 243-254.

[12] N.C. Kar, H. M. Jabr, “A novel PI gain scheduler for a vector controlled doubly-fed wind driven induction generator, in: Proceedings of $8^{\text {th }}$ IEEE Int. Conf. Electrical Machines and Systems, vol. 2, 2005, pp.948-953.

[13] J. Zhao, W. Zhang, Y. He, J. Hu, "Modeling and Control of a WindTurbine-Driven DFIG Incorporating Core Saturation during Grid Voltage Dips", Electronic Machines and Systems (ICEMS), 2008, pp.2438-2442.
[14] H.M. Jabr , N.C. Kar, "Effects of main and leakage flux saturation on the transient performances of doubly-fed wind driven induction generator", Electric Power Systems Research, Vol. No.8, 2007, pp 1019-1027.

[15] H.M. Jabr, N.C. Kar, "Leakage flux saturation effects on the transient performance of wound rotor induction motors", Electric Power Systems Research, vol. 78, 2008, PP.1280-1289.

[16] M. Iordache, L. Dumitriu, "Voiculescu, R. Nicolae, D., Galan, N.: Saturated Induction Machine Steady-state Performance assessment through simulations", IEEE transactions on energy conversion, 2014, pp. 368-374.

[17] H.M. Jabr, N.C. Kar, "Starting performances of saturated induction motors", In: Proc. IEEE. Conf, Power Engineering Society General Meeting, Tampa Florida, USA, 24-28 June, 2007, pp. 1-7.

[18] S. Mefoued, "A second order sliding mode control and a neural network to drive a knee joint actuated orthosis", Neurocomputing 2015, vol. 155, pp. 71-79.

[19] X. Yao, Y. Jing, Z. Xing. "Direct torque control of a doubly-fed wind generator based on grey-fuzzy logic", In: International Conference on Mechatronics and Automation, 2007, Harbin, China. pp. 3587-3592.

[20] G.S. Buja, M.P. Kazmierkowski, "Direct torque control of PWM inverter-fed AC motors - a survey", IEEE T Ind Electron 2004, vol. 51, pp. 744-757.

[21] S.Z. Chen, N.C. Cheung, K.C. Wong, J. Wu, "Integral sliding-mode direct torque control of doubly-fed induction generators under unbalanced grid voltage", IEEE Trans. Energy Conver. 2010, vol. 25, pp. 356-368.

[22] A. Levant, L. Alelishvili, "Integral high-order sliding modes", IEEE T Automat Contr, vol. 52, 2007, pp. 1278-1282.

[23] A. Levant, "Higher-order sliding modes, differentiation and output feedback control", Int J Control, 2003; vol. 76, pp. 924-941.

[24] X. Zhu, S. Liu, Y. Wang, "Second-order sliding-mode control of DFIGbased wind turbines", In: IEEE $20143^{\text {rd }}$ Renewable Power Generation Conference; 24-25 September 2014, Naples, Italy, pp. 1-6.

[25] N. C. Kar, H. M. Jabr, "A novel PI gain scheduler for a vector controlled doubly-fed wind driven induction generator", in: Proceedings of $8^{\text {th }}$ IEEE Int. Conf. Electrical Machines and Systems, vol. 2, 2005, pp.948953.

[26] P. Kundur, "Power Systems Stability and Control", New York, McGraw-Hill, USA, 1994, pp. 296-297.

[27] G. J. Rogers, D. S. Benaragama, An induction motor model with deepbar effect and leakage inductance saturation", Arch Elektrotech, vol. 60, 1978, pp. 193-201.

[28] B. Beltran, M.E.H. Benbouzid, T. Ahmed-Ali, "High-order sliding mode control of a DFIG-based wind turbine for power maximization and grid fault tolerance", In: IEEE International Electric Machines and Drives Conference, May 2009; Miami, Florida, USA, pp. 183-189. 